\title{
Impact of Histopathological Factors, Patient History and Therapeutic Variables on Recurrence-free Survival after Ductal Carcinoma in Situ: 8-Year Follow-up and Questionnaire Survey
}

\author{
Einfluss histopathologischer, anamnestischer und therapeutischer Variablen nach Erkrankung am \\ duktalen Carcinoma in situ auf die rezidivfreie Zeit: 8-Jahres-Follow-up und Fragebogenuntersuchung
}

Authors

Affiliation
M. T. van Mackelenbergh, C. M. Lindner, T. Heilmann, I. Alkatout, M. Elessawy, C. Mundhenke, N. Maass, C. Schem

Obstetrics and Gynecology, University Hospital Center Schleswig-Holstein, Campus Kiel, Kiel
Deutsche Version unter: www.thieme-connect.de/ ejournals/gebfra

\section{Abstract \\ $\nabla$}

Introduction: Ductal carcinoma in situ (DCIS) is a premalignant lesion of the glandular component of the breast and a precursor lesion of invasive breast cancer. In recent decades the incidence of DCIS has risen continuously, mainly because of more extensive screening and more advanced diagnostic procedures. There is an increasing need for evidence-based treatment guidelines which will protect patients as far as possible from recurrence or invasive cancer but also from overtreatment. This retrospective single-center clinical trial analyzed recurrence-free survival times, rates of invasive and non-invasive events, and the impact of patient history, histopathological variables and therapeutic factors on recurrence-free survival times.

Material and Methods: A total of 200 patients who underwent surgery between 2000 and 2007 for pure DCIS were included in the study. As part of follow-up a questionnaire was sent to patients and their respective gynecologists.

Results: In the follow-up period, $12.5 \%(\mathrm{n}=25)$ of the 200 patients had recurrence (invasive or noninvasive event). Menopausal status, tumor grade and tumor size were significantly associated with recurrence. Low-grade DCIS was significantly more often hormone receptor-positive than high-grade DCIS. Patients who had postoperative radiotherapy significantly more often also received endocrine drug treatment. There was a significant association between younger patient age and drug treatment. The study found that in the investigated cohort, premenopausal women had a significantly shorter recurrence-free time compared to postmenopausal women.

Conclusion: This paper summarizes the current literature on DCIS. There is a need for more prospective clinical trials to improve the prognosis of premenopausal women with large and hormone receptor-positive DCIS.

\section{Zusammenfassung \\ $\nabla$}

Einleitung: Das duktale Carcinoma in situ der Brust (DCIS) ist eine prämaligne Neoplasie des Brustdrüsengewebes und unmittelbare Vorläuferläsion des invasiven Mammakarzinoms. Seine Inzidenz ist in den vergangenen Dekaden sprunghaft angestiegen. Folglich werden Richtlinien benötigt, die einerseits einen größtmöglichen Schutz vor DCIS-Rezidiven bzw. invasiven Karzinomen bieten, andererseits aber auch keine Übertherapie darstellen. Die vorliegende Arbeit untersucht neben der Dauer der rezidivfreien Zeit und der Ereignisrate (invasiv und noninvasiv) den Einfluss anamnestischer und histopathologischer Variablen, sowie therapeutischer Maßnahmen auf die rezidivfreie Zeit nach der Diagnose eines DCIS.

Material und Methoden: Eingeschlossen wurden 200 Patientinnen, die in den Jahren 2000 bis 2007 an einem reinen DCIS operiert wurden. Zur Erfassung des Follow-ups wurde ein Fragebogen an die Patientinnen und den behandelnden Gynäkologen verschickt.

Ergebnisse: Im Nachbeobachtungszeitraum kam es bei $12,5 \%(n=25)$ der 200 Patientinnen zu einem Rezidivereignis. Der Menopausenstatus, Malignitätsgrad und Tumorgröße waren signifikant mit der Rezidivrate assoziiert. Die niedrigmalignen DCIS waren ebenfalls signifikant häufiger kleiner und hormonrezeptorpositiv als hochmaligne. Patientinnen, die eine postoperative Radiatio durchführten, nahmen signifikant häufiger auch eine medikamentöse endokrine Therapie ein. Signifikant war ebenso der Zusammenhang zwischen jungem Patientinnenalter und der Einnahme einer medikamentösen Therapie. Die vorliegende Arbeit konnte für die untersuchte Kohorte nachweisen, dass prämenopausale gegenüber postmenopausalen Frauen eine signifikant kürzere rezidivfreie Zeit aufweisen. 
Schlussfolgerung: Dieser Artikel gibt einen aktuellen Überblick über die Literatur zum DCIS. Weitere prospektive Studien zur Untersuchung des Rezidivrisikos prämenopausaler Patientinnen, die an größeren und hormonrezeptorpositiven DCIS-Tumoren erkranken, sind notwendig, um Morbidität und Mortalität in dieser Patientinnengruppe zu senken.

\section{Introduction \\ $\nabla$}

Ductal carcinoma in situ (DCIS) is a neoplastic disease of glandular breast tissue characterized by an expansive growth of malignant epithelial cells, particularly in the area of the terminal ductal-lobular units (TDLU). As the definition suggests, these are in situ lesions whose expansion is limited by the basal membrane of the duct; they have no potential to metastasize [1]. Retrospective studies $[2,3]$ have described a transformation from inadequately treated DCIS to invasive carcinoma. Histologically, DCIS are classified into five different subtypes based on their architectural growth patterns [4]: these are comedo, cribriform, papillary, solid, or micropapillary subtype. Estrogen receptor expression has been reported in around 75\% of all DCIS, and expression is prognostically and therapeutically relevant [5]. In the 1990s, the American pathologist Michael D. Lagios described three different histological grades for DCIS [6]: low-grade, intermediate and high-grade DCIS. The grades differ with regard to their nuclear grade of malignancy and the presence or absence of comedo necrosis. In the 1990s, Silverstein et al. developed the Van Nuys Prognostic Index (VNPI) which included tumor size and tumorfree resection margins in addition to nuclear grade and the presence or absence of comedo necrosis. The VNPI aimed to provide information on prognosis and assist physicians when making treatment recommendations [7]. As patient age was also found to affect outcomes, this parameter was also included in the Index, and the modified University of Southern California/Van Nuys Prognostic Index (USC/VNPI) was published in 2002 [8].

Following the nationwide introduction of mammogram screening in Germany, the number of women diagnosed with DCIS increased rapidly. Based on recent trends it is expected that between $20-25 \%$ of all newly diagnosed breast tumors will be DCIS [9]. Between 1980 and 2001 the number of cases diagnosed with DCIS increased sevenfold, with this increase mainly recorded for the group of women aged over 50 years [10]. The biggest risk factor for the diagnosis of a DCIS is a prior mammogram as most cases are diagnosed as incidental findings in otherwise asymptomatic women [11]. As with breast cancer, longer exposure to estrogen over the patient's lifetime as a consequence of early menarche and late menopause, nulliparity or late first pregnancy, no breastfeeding or only a short period of breastfeeding, and obesity in postmenopausal women is recognized to be a well-known risk factor for developing DCIS [12,13]. Some studies have investigated the association between DCIS and "lifestyle" factors such as smoking behavior, alcohol consumption or physical activity without being able to clearly identify risk factors $[14,15]$.

Radical surgical therapy (mastectomy) results in a cure in $98 \%$ of cases [16]. The following clinical situations are considered clear indications for mastectomy: diffuse micro-calcifications in the breast with tumor-free resection margins difficult or impossible to verify; adjuvant radiotherapy contraindicated; unfavorable ratio of tumor to breast size; and the patient's own request [17]. In smaller and lower grade lesions mastectomy is considered to be overtreatment; breast-conserving therapy (BCT) consisting of lumpectomy with tumor-free resection margins is the treatment of choice for these lesions. A recent meta-analysis came to the conclusion that the optimal tumor-free resection margin was a margin of more than $10 \mathrm{~mm}$ [15]. Adjuvant radiotherapy after breast-conserving surgery is recommended; however, the "side effects and disadvantages of radiotherapy (...) must be weighed against the reduction of risk". Boost irradiation is particularly recommended for younger patients, as younger age is considered an independent prognostic factor for local recurrence (AGO Guidelines Breast, version 2013). In the past, radiotherapy was not generally indicated for all DCIS. Adjuvant drug therapy should be considered for patients with receptor-positive DCIS. The antiestrogen tamoxifen is the most commonly used drug, often administered over 5 years [18]. The benefit is well documented; in practice, however, the therapy is not used much because of the associated side effects which include a risk of secondary malignant carcinoma (endometrial carcinoma).

Factors associated with an increased risk of recurrence are tumor size, grading, receptor status, resection margins and patient age [19]. Other studies have looked at biomarkers which could provide information about the biological behavior of DCIS and help to estimate prognosis. The role played by the proteins p53 and Ki-67 in tumorigenesis has been studied $[20,21]$.

The aim of this study was to retrospectively analyze the data of all patients who underwent initial surgery for DCIS between 2000 and 2007 in the Department for Gynecology and Obstetrics of the University Hospital Center Schleswig-Holstein, Campus Kiel, and determine the recurrence-free period for this cohort and examine whether there were statistically relevant correlations between patient history, histopathological factors or therapeutic variables and recurrence-free survival. The study additionally aimed to investigate whether there were statistically significant relationships between patient history, histopathological findings and the different therapeutic variables.

\section{Material and Methods \\ $\nabla$}

\section{Patient cohort}

This study analyses the data of all female patients who underwent surgery for ductal carcinoma in situ between 2000 and 2007 in the Department for Gynecology and Obstetrics of the University Hospital Center Schleswig-Holstein, Campus Kiel. All of the patients in the cohort were treated before radiotherapy for DCIS was considered generally indicated. This allows the impact of radiotherapy to be evaluated. Inclusion criteria were female gender and a primary diagnosis of pure DCIS without micro-invasion. Exclusion criteria were defined as additional micro-invasion and male gender.

\section{Data collection}

Data were collected retrospectively from the records of the Department for Gynecology and Obstetrics of the University Hospital Center Schleswig-Holstein, Campus Kiel; the Institute for Pa- 
thology of the University Hospital Center Schleswig-Holstein, Campus Kiel; and the Radiotherapy Department of the University Hospital Center Schleswig-Holstein, Campus Kiel. The approval of the ethics committee of the Medical Faculty of Kiel University (Christian-Albrechts-Universität Kiel) was obtained prior to commencing the study (File number: D452/13). The spreadsheet program Microsoft Excel (Microsoft Office, USA, 2007) was used to record the data. The start of the observation period was defined as the date of primary surgery for each individual. The end of the observation period was given as August 31,2009, as this was the date on which the questionnaires were sent out. The following patient data were collected: date of birth, menopausal status, adjuvant therapies, date of surgery, surgical method used, tumor grade, tumor size, resection margins, and hormone receptor status. Follow-up was done using a standardized written questionnaire, which was sent to patients requesting information on the following points: age at primary diagnosis, contraceptive and postmenopausal hormone intake, smoking, familial and personal history with respect to malignant disease, type of surgery, postoperative therapy (repeat surgery, radiotherapy), regular followup mammograms, and DCIS recurrence or the development of invasive breast cancer. A questionnaire was sent to the patients' gynecologists asking about the time of the last contact between physician and patient, the patient's state of health, and whether the patient had developed recurrence or malignant disease. Recurrence of ductal carcinoma in situ or development of invasive carcinoma were defined as the primary endpoints of the study. Because of the small number of cases, in this study the two endpoints were summarized as a single "event".

\section{Statistical analysis}

Statistical data analysis was done using SPSS (Statistical Package for the Social Sciences, IBM, USA). Survival probabilities were calculated using the Kaplan-Meier method. Pearson's $\mathrm{X}^{2}$-test was used to analyze relationships between categorical variables. The level of significance was set at $5 \%$. The arithmetic mean was calculated for normally distributed data; the median was calculated for non-normally distributed variable. Bonferroni correction of alpha error was done for multivariate analysis.

\section{Results}

$\nabla$

\section{Patient cohort}

Mean age of the investigated cohort at primary diagnosis was 58 years (minimum: 35 years, maximum: 83 years). The median follow-up period was 6.8 years. The health status could not be determined for 25 of the 200 patients included in the study, as neither the patient nor her gynecologist returned the questionnaire. The response rate was $87.5 \%$. For better evaluation, patients were divided into 2 groups stratified by age, with one group consisting of patients up to the age of 60 and the second group consisting of patients aged 60 and above. In all, 108 (54\%) patients were younger than 60 years at primary diagnosis; 92 patients (46\%) were older than 60 years at primary diagnosis. A total of 39 patients (19.5\%) were premenopausal at the time of primary diagnosis; 144 (72\%) patients were postmenopausal. Information on menopausal status at primary diagnosis was lacking for 17 patients (8.5\%). Of 135 patients, 58 (43\%) had hormone replacement therapy; 77 patients (57\%) did not take any hormone preparations. At the time of primary diagnosis only 4 patients $(2.9 \%)$ were taking oral contraceptives. Data on smoking behavior was available for

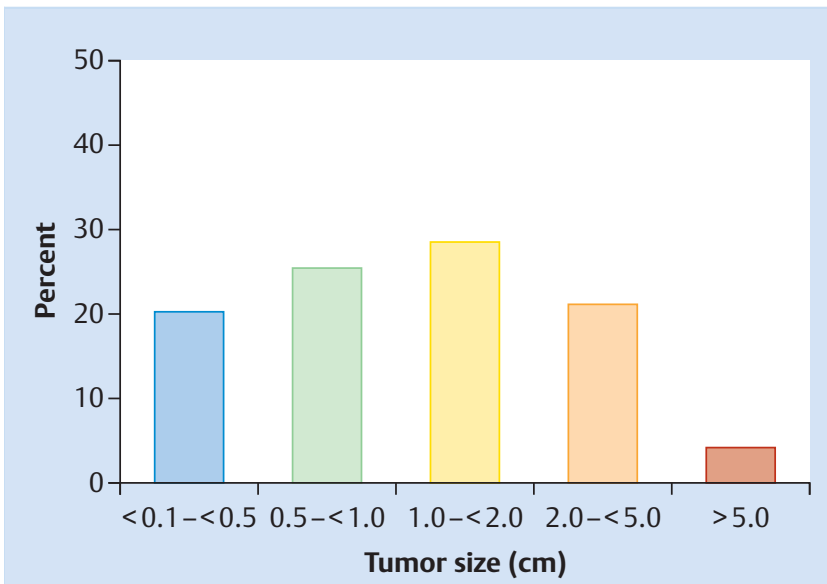

Fig. 1 Distribution of tumor sizes. Classification into subgroups was done analogously to the TNM classification.

Table 1 Distribution of DCIS grade of malignancy in the patient cohort in percent.

\begin{tabular}{|l|l|l|}
\hline Histological grade & Patients $(\mathbf{n})$ & $\begin{array}{l}\text { \% of the patient cohort } \\
25.5\end{array}$ \\
\hline Low-grade DCIS & 51 & 44 \\
\hline Intermediate DCIS & 88 & 30.5 \\
\hline High-grade DCIS & 61 & \\
\hline
\end{tabular}

137 patients. Of this group, 49 patients (35.7\%) had a history of smoking; 88 of 137 patients (64.3\%) reported that they had never smoked. Out of 181 patients with a known family history, 86 $(47.5 \%)$ had relatives who had also had DCIS.

The distribution of malignant nuclear grades based on the histological evaluation of the cohort is given in $\bullet$ Table 1 . Tumor sizes ranged from $0.1 \mathrm{~mm}$ to $12 \mathrm{~cm}$; evaluation was based on the stratification of patients into 5 groups. A total of 39 patients (19.5\%) had tumors with diameters between 0.1 and $0.49 \mathrm{~cm} ; 49$ patients (24.5\%) had tumors with diameters between 0.5 and $0.99 \mathrm{~cm}$; $27.5 \%$ of the cohort ( 55 patients) had tumors with diameters between 1 and $1.99 \mathrm{~cm}$; and $20.5 \%$ of the cohort ( 41 patients) had tumors with diameters between 2 and $4.99 \mathrm{~cm}$. Eight patients (4\%) had tumors larger than $5 \mathrm{~cm}$ ( $\bullet$ Fig. 1). Lesions with resection margins of less than $5 \mathrm{~mm}$ were removed in 79 of $189 \mathrm{pa}-$ tients $(41.8 \%)$, while 31 patients (16.4\%) had a tumor-free resection margin of between 5 and $10 \mathrm{~mm}$, and a further 79 patients (41.8\%) had relatively larger tumor-free margins of $>10 \mathrm{~mm}$. Of the 138 cases with known hormone receptor status, 112 patients (81.2\%) were estrogen receptor-positive, and 94 patients (68.2\%) were progesterone receptor-positive. Accordingly, 26 tumors (18.8\%) were estrogen receptor-negative, and 44 patients (31.8\%) were progesterone receptor-negative.

Segment resection was the primary surgical procedure of choice in 177 of 200 patients (88.5\%); the remaining 20 patients (10\%) underwent mastectomy as their primary surgical procedure. Subsequently, 88 of 200 patients (44\%) had a second operation during follow-up. At this second intervention a further 25 patients (28.4\% of re-operated patients) had a mastectomy. Breastconserving follow-up resection was done in 63 cases $(71.5 \%$ of 88 ). Five patients ( $2.5 \%$ of the cohort) required a third operation; all 5 of these third procedures were mastectomies. At the end of 


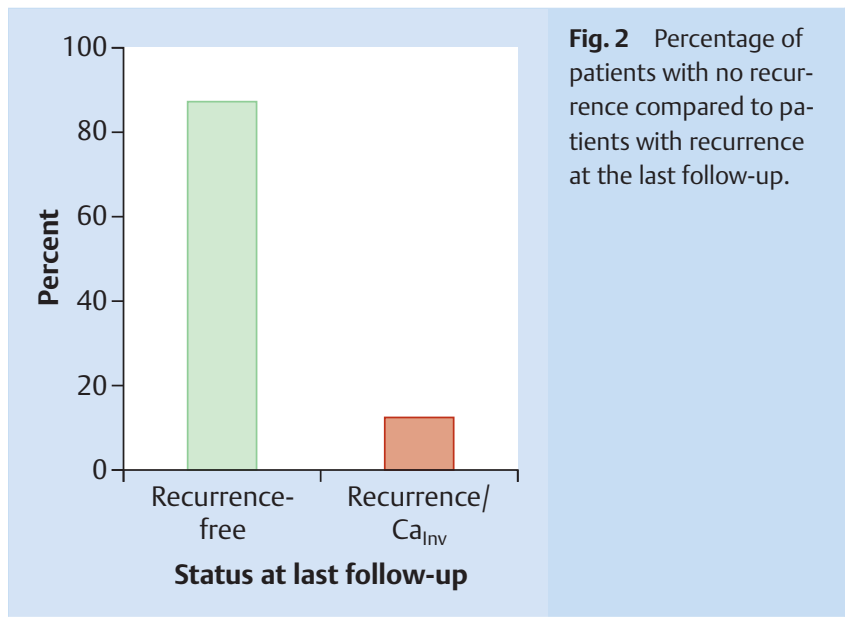

follow-up a total of 50 women (25\% of the total cohort) had undergone mastectomy. Adjuvant drug therapy was administered to 97 patients (48.5\%), 82 of patients $(84.5 \%)$ underwent anti-estrogen therapy with tamoxifen (e.g. Nolvadex ${ }^{\circledR}$ ), and $15.5 \%$ (15 patients) received an aromatase inhibitor such as anastrozole (Arimidex ${ }^{\circledR}$ ). This was administered in the context of the IBIS-II trial. Adjuvant radiotherapy was given to 80 patients ( $41 \%$ of the overall cohort), while 115 women (58.9\%) did not receive radiotherapy (this figure includes the 50 patients with mastectomy for whom radiotherapy was not indicated); no data on radiotherapy is available for 5 patients.

During follow-up, an "event" occurred in 25 patients (12.5\%) ( Fig. 2). The mean recurrence-free period in our cohort was 108 months (95\% confidence interval [CI]: 103-115 months) (๑ Fig. 3).

\section{Correlations with recurrence-free survival}

The mean recurrence-free survival depending on the malignancy grade of the DCIS was 115 months (95\% CI: 106-125 months; rate of recurrence: $7.8 \%$ [4 of 51]) for patients in the low-grade group; it was 110 months (95\% CI: 101-118 months; rate of recurrence: $13.7 \%$ [ 12 of 88 ]) for the intermediate grade group and 93 months (95\% CI: 79-108 months, rate of recurrence: 14.8\% [9 of 61]) for patients in the high-grade group. Log-rank sum test was used to analyze equality between groups and calculated a p-value of 0.110 for the distribution of the recurrence-free period between the different malignancy grades ( Fig. 4), indicating a slight trend towards an advantage with regard to recurrence-free time for patients with low-grade DCIS. In the total population, analysis of the pathological-histological variables "tumor size" ( $p=0.690$, log-rank sum test), "tumor-free resection margin" $(p=0.271)$, "estrogen receptor status" $(p=0.388)$, and "progesterone receptor status" ( $p=0.882)$ showed no statistically significant impact on the primary endpoint.

Log-rank sum test analysis found a statistically significant correlation ( $p=0.008$ ) between a longer recurrence-free period and the variable "menopausal status" for patients who were already postmenopausal at the time of diagnosis (9.7\% recurrence rate vs. $23 \%$ ). No statistically significant impact on the primary endpoint was found for the remaining variables "age" $(p=0.278$, log-rank sum test), "familial history" ( $p=0.706)$, "adjuvant drug therapy" ( $p=0.635)$, "hormone replacement therapy" ( $p=0.989)$, “smoking” ( $p=0.201)$, or "radiotherapy" $(p=0.989)$.

The study also investigated whether there was a correlation between pathological-histological parameters and patient history. Therapeutic treatments and patient and tumor parameters were also analyzed to investigate possible connections between these parameters and the decision for specific therapeutic options. The analysis examined whether there was a correlation between the size of an excised tumor and its malignancy grade. Because of the limited number of cases, tumors were divided into two groups according to size $(\leq 2 \mathrm{~cm}$ and $>2 \mathrm{~cm})$ to obtain a meaningful result. It was found that in the investigated cohort larger tumors were more commonly associated with a higher malignancy grade compared to smaller tumors, and this correlation was statistically highly significant $(\mathrm{p}<0.0001)$. In addition the study analyzed whether there was a correlation between receptor status of the tumor and malignancy grade. Overall, the percentage of receptor-positive tumors was higher for low-grade tumors compared to high-grade tumors. The correlation was highly significant with $\mathrm{p}<0.0001$ for both estrogen receptor status (log-rank test: 18.435) and progesterone receptor status (log-rank test: 20.044). When therapy with aromatase inhibitors was grouped together with anti-estrogens as "adjuvant drug therapy", statisti-

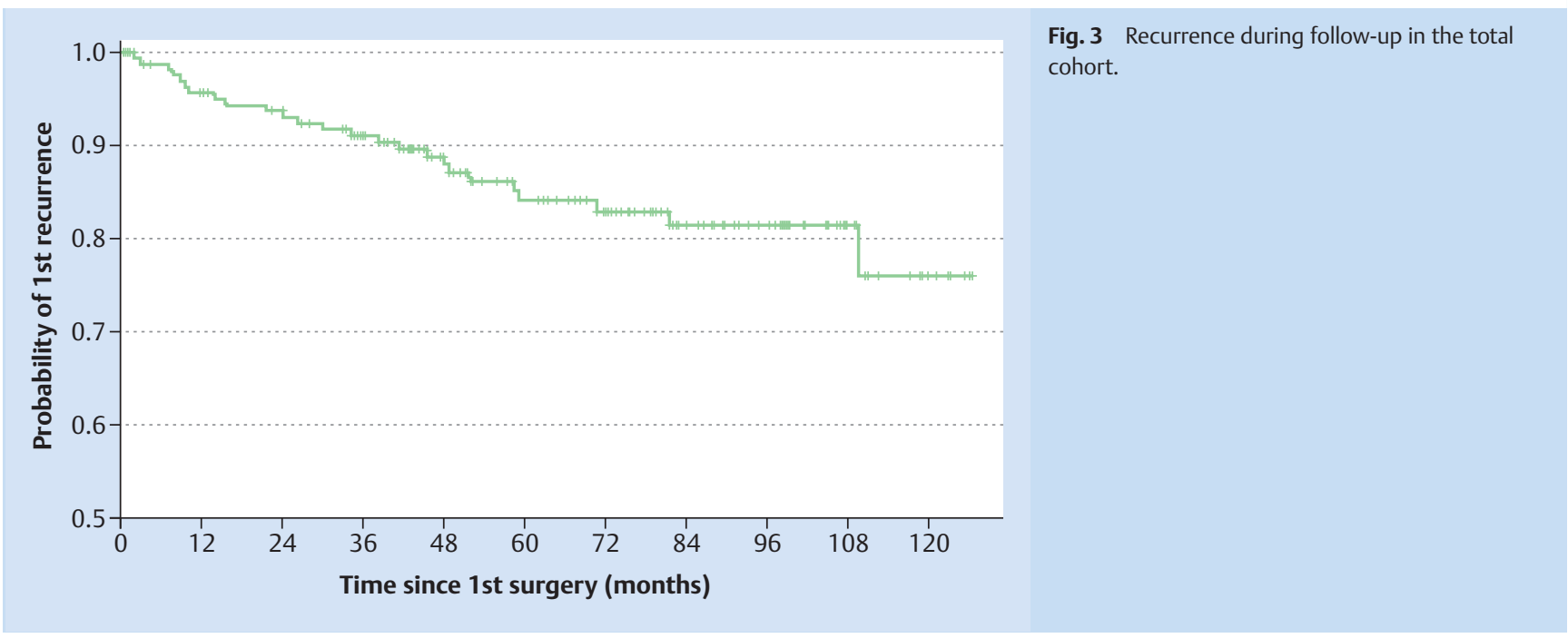




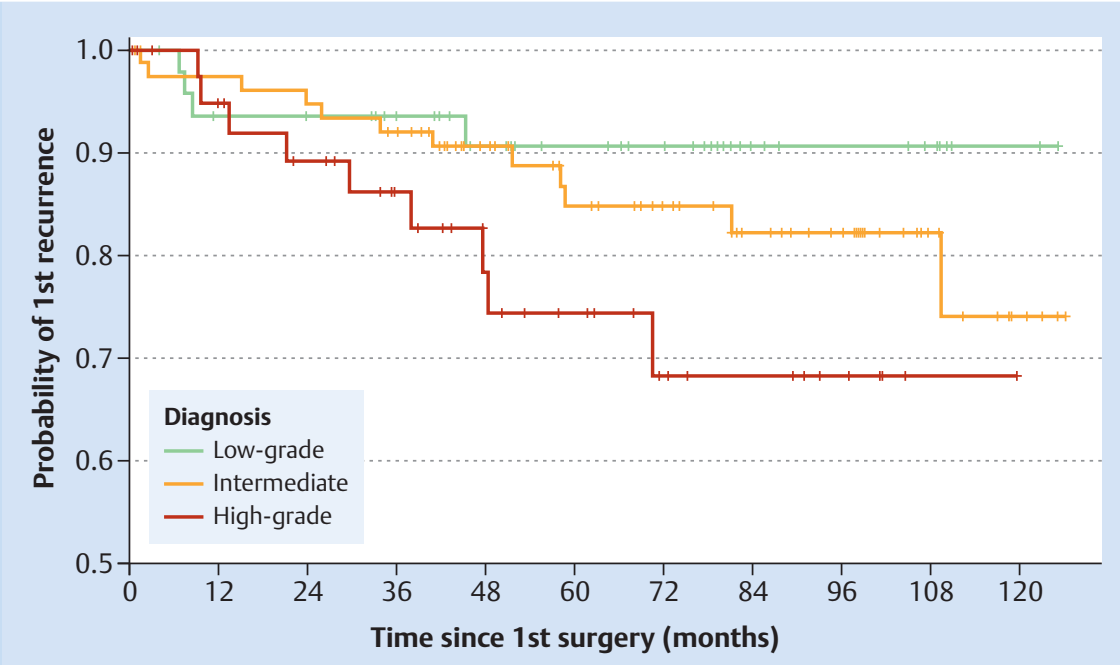

Fig. 4 Recurrence in the subgroups categorized according to malignancy grade.

cal analysis showed that patients who underwent radiotherapy postoperatively also had adjuvant drug therapy more often ( $p<0.0001$ [log-rank test: 29.517]). Particularly younger patients had adjuvant drug therapy significantly more often. The correlation was significant with a p-value of 0.002 (log-rank test: $10,563)$. Younger patients were more likely to have a positive history of smoking than older patients, and the difference between the two groups was statistically significant $(\mathrm{p}=0.026$; log-rank test: 5.128).

Analysis of the therapies raised the questions whether and to what extent the risk of recurrence could be reduced by the various interventions. The recurrence rate for the group of patients treated with radiotherapy was $4.6 \%$ compared to $7.7 \%$ for the group of women without radiotherapy. This corresponds to a risk reduction subsequent to postoperative radiotherapy of $3.1 \%$ in absolute terms. When combined with endocrine therapy the study found a clear benefit. A total of 52 patients had radiotherapy plus endocrine therapy; 4 of these patients had recurrence, which corresponds to a recurrence rate of $2 \%$ (with regard to the total cohort). The rate of recurrence for the other patients who had not received this combination of therapies (i.e., who had received either only radiotherapy or only endocrine therapy or neither) was $10.5 \%$. The combination of radiotherapy and endocrine therapy therefore resulted in a risk reduction of $8.5 \%$ in this cohort in absolute terms.

\section{Discussion}

$\nabla$

The investigated cohort consisted of 200 patients who received a primary diagnosis of pure DCIS between 2000 and 2007. When the effect of malignancy grade on recurrence-free time was analyzed, there was a slight trend to a longer recurrence-free period for women with lower grade tumors. Analysis showed that menopausal status and recurrence-free survival were correlated and the correlation was statistically highly significant. The association between malignancy grade and tumor size was also statistically significant. High-grade DCIS were larger than low-grade DCIS and this correlation was statistically significant. Low-grade DCIS were also statistically significantly more likely to be hormone receptor-positive. Significantly more patients who underwent radiotherapy postoperatively also had endocrine drug therapy compared to patients who did not undergo radiotherapy. The correlation between younger patient age and drug therapy was also statistically significant.

No effect of postoperative radiotherapy on recurrence-free survival was found in this study. However, other studies have found a correlation. The first results of the NSABP B-17 trial reported an incidence of DCIS recurrence of $8.2 \%$ in the group treated with radiotherapy (compared to $13.4 \%$ in the group which did not undergo radiotherapy) and an incidence of 3.9\% for invasive cancer (compared to $13.4 \%$ ). No effect on overall survival was found [22]. These results were confirmed in a new long-term follow-up study thirteen years later [23]. A prospective randomized clinical trial was carried out as part of protocol 10853 of the EORTC (European Organization for Research and Treatment of Cancer), and all participating women in the trial underwent breast-conserving surgery with some of them additionally receiving adjuvant radiotherapy [24]. After four years the risk reduction for DCIS recurrence in the group treated with radiotherapy was 35\% and the risk reduction for invasive carcinoma was $40 \%$. At 10 years' follow-up the benefit of radiotherapy was even more pronounced: the risk was reduced by $48 \%$ (for recurrence) and $42 \%$ (for invasive carcinoma) [25]. In summary, all prospective studies came to the conclusion that adjuvant radiotherapy after primary treatment for DCIS reduced the risk of local recurrence (with DCIS recurrence and invasive carcinoma grouped together). None of the studies found that radiotherapy had an effect on overall survival.

Another adjuvant therapy used when treating patients with DCIS is endocrine drug therapy. In our cohort, 82 women received tamoxifen, 15 women received anastrozole and 62 women did not have any drug treatment. If both groups receiving drug therapy are combined, the rate of recurrence was $10.3 \%$, which is only marginally under the rate for the group which did not receive drug therapy. However, when the study looked at the time of recurrence, it was found that recurrence occurred markedly earlier in the group without adjuvant drug therapy. The mean period of latency between primary diagnosis and recurrence was 25 months for the group which did not receive drug therapy, 53 months for the group treated with an aromatase inhibitor, and 42 months for the group treated with an estrogen receptor inhibitor. The large prospective studies which investigated the effect of radiotherapy in DCIS also investigated the effects of drug therapy 
in their analysis. Protocol B-24 of the NSABP trial prospectively randomized 1804 women into one of two treatment groups: lumpectomy plus radiotherapy plus tamoxifen and lumpectomy plus radiotherapy plus placebo [18]. The rate of local recurrence in the first group was $8.2 \%$ after five years; the rate in the placebo group was $13.4 \%$. The UKCCCR trial [26] also showed a reduction of DCIS recurrence after treatment with tamoxifen but found no reduction in the rate of invasive carcinomas.

In the literature, risk factors for local recurrence in patients with DCIS include high malignancy grade and the presence of comedo necrosis. Large tumors, small tumor-free margins and younger age at primary diagnosis have also been reported to increase the risk of recurrence $[19,27]$. In this cohort, the rate of recurrence increases as the grade of malignancy increases. The rate of recurrence for low-grade tumors was $7.8 \%$; it was $13.7 \%$ for intermediate tumors, and $14.8 \%$ for high-grade tumors. While this result is consistent with the expectation that tumors with a higher degree of malignancy are also more likely to recur, no effect of tumor size on recurrence rate was found for the investigated cohort nor was it possible to find a correlation between tumor-free resection margins and the rate of recurrence. However, it was found that highly malignant tumors tended to be bigger than tumors with low malignancy, and this correlation between malignancy and size was statistically significant. In the NSABP B-17 protocol Fisher et al. confirmed that the risk of recurrence was higher for DCIS with a malignant nuclear grade, existing comedo necrosis and small tumor-free margin [22]. Other pathological parameters (histological subtype, lymph node infiltration, tumor focus, cancerization and tumor infiltration of the connective tissue) were also examined. The study also investigated whether, based on these parameters, it was possible to identify a subgroup which benefitted less from radiotherapy, in other words, whether it was possible to identify patients who could do without adjuvant radiotherapy. This was not the case; on the contrary, the study found that all subgroups benefitted equally from radiotherapy. Even when cases were classified retroactively according to the USC/VNPI classification it was not possible to identify a score where the authors considered foregoing adjuvant radiotherapy was justifiable. It is possible that concepts will be developed for some subgroups in analogy to those for invasive carcinoma, for example with respect to hypofractionated radiotherapy.

In the cohort in our study no correlation could be established between the size of the tumor-free resection margin and the rate of recurrence. As the resection margin is the only pathological criterion which the surgeon can influence, there has long been a particular focus on tumor-free resection margins. Over time there have been a number of different estimations about the size of the tumor-free resection margin which can be considered safe. In 1999 Silverstein et al. published a retrospective analysis of the data of 469 female patients with DCIS who underwent breast-conserving surgery between the years 1979 and 1998 [28]. An analysis of their data showed no benefit of radiotherapy for patients with a tumor-free resection margin $>1 \mathrm{~cm}$. Radiotherapy also did not decrease the risk of recurrence in patients with tumor-free resection margins between 1-10 mm. Only patients with a tumor-free resection margin $<1 \mathrm{~mm}$ benefitted from radiotherapy.

This study consists of a retrospective analysis of data. The general limitations of the study are incomplete data, vulnerability to being influenced by confounders which may not be recognized as such, and the risk of misinterpretation of data because of a preconceived hypothesis [29]. Another weakness of the investigated data is the limited number of cases and the relatively short period of follow-up. These results are therefore entirely exploratory and cannot claim to serve as guidelines in clinical practice. Nevertheless, important basic principles were identified in this cohort that have highlighted important questions which are still unresolved. A prospective randomized study is the method of choice to obtain results which can be used to make treatment recommendations. Although with just 200 patients the cohort was on the small side, at the same time this was a highly selected patient population, as it covered all patients with a primary diagnosis of DCIS treated between 2000 and 2007 in the Department for Gynecology and Obstetrics of the University Hospital Center Schleswig-Holstein, Campus Kiel who met the inclusion criteria. Although in places the follow-up was incomplete, the survey of patients and their gynecologists supplemented by data collection done by telephone resulted in a very high rate of response of $87.5 \%$.

As previously mentioned, meaningful prognostic parameters which could make the treatment of DCIS safer with better targeting of individual patients are still lacking. In 2010 Pinder and colleagues presented a new DCIS classification [30]. Based on data from the UKCCCR/ANZ-DCIS trial, several pathological parameters were investigated to assess their impact on patient outcomes. In addition to standard parameters such as tumor size, patient age, nuclear grade and resection margins, attention also focused on histological characteristics. The histological architecture, the presence or absence of micro-calcifications and necrosis status were evaluated in multivariate analysis to assess their impact on recurrence-free survival. Following the results of these studies, a new four-tiered DCIS classification system was proposed [31] which would include identification of a high-risk group (very high-grade DCIS). Consequently Pinder et al. recommend that this group receive "maximum local treatment", i.e. mastectomy. They were unable to identify any group where foregoing radiotherapy would be recommended.

Other newer approaches have looked more closely at the molecular properties of DCIS and possible genetic and epigenetic changes. In 2008 Allred et al. compared the expression of different biomarkers in DCIS tissue with the expression of these markers in invasive cancers to obtain a better understanding of the biological behavior and the development of invasive carcinomas out of precancerous lesions [32]. Other working groups are currently investigating the role of molecular markers in prognosis using tissue excised from DCIS. Kerlikowske et al. published the results of their molecular investigations in 2010 [33]. They examined the expression of different markers such as hormone receptors, antigens Ki67, p63 and p16, HER2/neu receptors and COX-2 in DCIS tissue and the relationship between these markers and prognosis. They were able to show that triple-positive DCIS (p16, COX-2, Ki-67) is associated with a significantly higher risk of developing into invasive cancer.

\section{Conclusion}

\section{$\nabla$}

As it has been possible to show the positive impact of radiotherapy and systemic therapy on overall recurrence-free survival, the focus of future DCIS research must be on identifying high-risk and low-risk patients to be able to offer therapy regimens targeted to the individual patient. Both overtreatment and undertreatment should be avoided. 


\section{Conflict of Interest}

$\nabla$

None.

\section{References}

1 Böcker W, Denk H, Heitz PU. Pathologie. 3. Aufl. München: Elsevier GmbH; 2004: 987-992

2 Betsill WL, Rosen PP, Lieberman PH et al. Intraductal carcinoma. Longterm follow-up after treatment by biopsy alone. JAMA 1978; 239: 1863-1867

3 Page DL, Dupont WD, Rogers LW et al. Intraductal carcinoma of the breast: follow-up after biopsy only. Cancer 1982; 49: 751-758

4 Lebeau A. Prognostische Faktoren beim duktalen Carcinoma in situ. Pathologe 2006; 27: 326-336

5 Tavassoli FA, Devilee P, eds. Pathology and Genetics of Tumors of the Breast and female genital Organs. Lyon: IARC Press; 2003

6 Lagios MD. Heterogeneity of duct carcinoma in situ (DCIS): relationship of grade and subtype analysis to local recurrence and risk of invasive transformation. Cancer Lett 1995; 90: 97-102

7 Silverstein MJ, Poller DN, Waisman JR et al. Prognostic classification of breast ductal carcinoma-in-situ. Lancet 1995; 345: 1154-1157

8 Silverstein MJ. The University of Southern California/Van Nuys Prognostic Index. In: Silverstein MJ, ed. Ductal Carcinoma in Situ of the Breast. 2nd ed. Philadelphia, PA: Lippincott, Williams and Wilkins; 2002: 459-473

9 Bobo JK, Lee NC, Thames SF. Findings from 752,081 clinical breast examinations reported to a national screening program from 1995 through 1998. J Natl Cancer Inst 2000; 92: 971-976

$10 \mathrm{Li} \mathrm{CI}$, Daling JR, Malone KE. Age-specific incidence rates of in situ breast carcinomas by histologic type, 1980 to 2001. Cancer Epidemiol Biomarkers Prev 2005; 14: 1008-1011

11 Kerlikowske K. Epidemiology of ductal carcinoma in situ. J Natl Cancer Inst Monogr 2010; 41: 139-141

12 Feigelson HS, Henderson BE. Estrogens and breast cancer. Carcinogenesis 1996; 17: 2279-2284

13 Kelsey JL, Bernstein L. Epidemiology and prevention of breast cancer. Annu Rev Public Health 1996; 17: 47-67

14 Virnig BA, Tuttle TM, Shamliyan T et al. Ductal carcinoma in situ of the breast: a systematic review of incidence, treatment and outcomes. J Natl Cancer Inst Monogr 2010; 41: 170-178

15 Wang SY, Chu H, Shamliyan T et al. Network meta-analysis of margin threshold for women with ductal carcinoma in situ. J Natl Cancer Inst 2012; 104: 507-516

16 Morrow M, Brinkmann E. Surgical Overview of the Treatment of ductal Carcinoma in Situ. In: Silverstein MJ, ed. Ductal Carcinoma in Situ of the Breast. 2nd ed. Philadelphia, PA: Lippincott, Williams and Wilkins; 2002: 275-286

17 Newman LA. Local control of ductal carcinoma in situ based on tumor and patient characteristics: the surgeon's perspective. J Natl Cancer Inst Monogr 2010; 41: 152-157

18 Fisher B, Dignam J, Wolmark $N$ et al. Tamoxifen in treatment of intraductal breast cancer; National Surgical Adjuvant Breast and Bowel Project B-24 randomised controlled trial. Lancet 1999; 353: 19932000
19 Lagios MD. Practical Pathology of Duct Carcinoma in Situ: how to derive optimal Data from the pathologic Examination. In: Silverstein MJ, ed. Ductal Carcinoma in Situ of the Breast. 2nd ed. Philadelphia, PA: Lippincott, Williams and Wilkins; 2002: 207-221

20 Ravdin PM. Prognostic Factors in ductal Carcinoma in Situ. In: Silverstein MJ, ed. Ductal Carcinoma in Situ of the Breast. 2nd ed. Philadelphia, PA: Lippincott, Williams and Wilkins; 2002: 49-53

21 Bundred NJ. Model Systems for ductal Carcinoma in Situ. In: Silverstein MJ, ed. Ductal Carcinoma in Situ of the Breast. 2nd ed. Philadelphia, PA: Lipincott, Williams and Wilkins; 2002: 77-86

22 Fisher B, Dignam JJ, Wolmark $N$ et al. Lumpectomy and radiation therapy for the treatment of intraductal breast cancer: findings from $\mathrm{Na}-$ tional Surgical Adjuvant Breast and Bowel Project; B-17. J Clin Oncol 1998; 16: 441-452

23 Wapnir IL, Dignam JJ, Fisher B et al. Long-term outcomes of invasive ipsilateral breast tumor recurrences after lumpectomy in NSABP B-17 and B-24 randomized clinical trials for DCIS. J Natl Cancer Inst 2011; 103: $478-488$

24 Julien JP, Bijker N, Fentiman IS et al. Radiotherapy in breast-conserving treatment for ductal carcinoma in situ: first results of the EORTC randomised phase III trial 10853. Lancet 2000; 355: 528-533

25 Bijker N, Meijnen P, Peterse JL et al. Breast-conserving treatment with or without radiotherapy in ductal carcinoma in situ: ten-year results of European Organization for Research and Treatment of Cancer randomized phase III trial 10853 - a study by the EORTC breast cancer cooperative group and EORTC radiotherapy group. J Clin Oncol 2006; 24 : 3381-3387

26 Houghton J, George WD, Cuzick J et al. Radiotherapy and tamoxifen in women with completely excised ductal carcinoma in situ of the breast in the UK, Australia, and New Zealand: randomized controlled trial. Lancet 2003; 362: 95-102

27 Sposto R, Epstein MS, Silverstein MJ. Predicting local Recurrence in Patients with ductal Carcinoma in Situ. In: Silverstein MJ, ed. Ductal Carcinoma in Situ of the Breast. 2nd ed. Philadelphia, PA: Lippincott, Williams and Wilkins; 2002: 255-263

28 Silverstein MJ, Lagios MD, Groshen S et al. The influence of margin width on local control of ductal carcinoma in situ of the breast. N Engl J Med 1999; 340: 1455-1461

29 Morton RF, Hebel JR. Some principles of epidemiologic studies. J Fam Pract 1979; 8: 781-785

30 Pinder SE, Duggan C, Elli IO et al. A new pathological system for grading DCIS with improved prediction of local recurrence: results from the UKCCCR/ANZ DCIS Trial. Br J Cancer 2010; 103: 94-100

31 Pinder SE. Ductal carcinoma in situ (DCIS): Pathological features, differential diagnosis, prognostic factors and specimen evaluation. Modern Pathology 2010; 23: 8-13

32 Allred DC, Wu Y, Mao S et al. Ductal carcinoma in situ and the emergence of diversity during breast cancer evolution. Clin Cancer Res 2008; 14 : 370-378

33 Kerlikowske K, Molinaro AM, Gauthier ML et al. Biomarker expression and risk of subsequent tumors afters initial ductal carcinoma in situ diagnosis. J Natl Cancer Inst 2010; 102: 627-637 